\title{
Preface
}

At the beginning of the twenty-first century the world must place the highest priority on constructing a sustainable socioeconomic system that can cope with the rapid ageing of populations in developed countries and with the limited environmental resources available in both developed and developing countries. At first glance, the problems of ageing and the environment may seem to be quite separate issues. However, they share a common feature: they both deal with intergenerational problems. The essence of the ageing problem is how to find effective ways for a smaller, working generation to support a larger, ageing generation. The crux of the environmental problem is to find a feasible way to leave environmental resources to future generations. Moreover, in terms of consumption, slower population growth may slow consumption and help to alleviate environmental problems. On the other hand, a rapidly ageing society may use more energy-intensive technology to compensate for the inevitable labor shortage, and thus cause a deterioration in the natural environment.

Today, these concerns are highly applicable in Japan. The pressure created by the rapid ageing of the Japanese population is becoming acute; Japan must construct a sustainable society that does not create intergenerational inequity or erode public welfare. At the same time, Japan cannot deplete its environmental resources and energy, as this would leave future generations with an unbearably heavy burden.

The Japanese government has recognized the vital importance of both problems. To explore and implement solutions for this difficult task, in April 2000 former Prime Minister Keizo Obuchi launched several comprehensive and interdisciplinary research projects known collectively as the 'Millennium Project'. As a consequence, in the same month, the Economic and Social Research Institute (ESRI), Cabinet Office, Government of Japan, initiated a two-year project entitled 'A Study on Sustainable Economic and Social Structure in the Twenty-first Century'. While the Millennium Project covers a wide range of topics and disciplines such as natural science and technological innovation, the project conducted by ESRI places major emphasis on social science. While taking into account technological innovation and feasibility, it focuses on ageing and environmental problems. It aims to design a desirable socioeconomic structure under the pressure of an ageing population and environmental constraints 
by identifying the necessary policy tools to attain stable and sustainable growth.

This project is being implemented with close collaboration among Japanese as well as foreign scholars and research institutes. Besides Japanese scholars and institutes, foreign participants have been involved from, among others, the United States, the United Kingdom, Norway, Austria, Italy, Australia, Korea and Thailand. In total there are ten countries and 30 working groups.

\section{AGEING SOCIETY}

The Japanese population is graying rapidly, and the elderly are expected to account for a quarter of the nation's total population in 2020. Japan needs to reform its social security system, pension management schemes, financial/capital markets and labor markets if it hopes to create a better and sustainable future society. When looking at Japan's problems head on, we see giant fiscal deficits, bad-loan problems, and long-term structural problems that must be fixed aggressively or suffered indefinitely. The clock is ticking, and the time to act is short, but our problems are not insurmountable. Pessimism is not our rallying call. Rather, we are optimistic, and encouraged by the European example. In Europe, countries have worked hard to improve fiscal conditions and social security, and they have attained positive results and succeeded in uniting their separate markets.

Studies on ageing populations can be divided roughly into three categories: (i) macroeconomic problems related to the decline in the workforce due to ageing; (ii) social security systems, with many of the studies looking at pension systems; and (iii) the labor market, for example, employment of the elderly, competition with younger workers, the female workforce, and immigrant workers. We have made a specialized study of our theme from these perspectives.

Many people are pessimistic about the effect of ageing on the macro economy due to the reduction in the labor force. However, in this study, there were others who expressed a challenging view that various impacts, including those on economic growth, can be coped with fully and overcome by technological progress and other measures. Some strongly suggested that the current economic and social system would need to be reformed to achieve the flexibility required. Accelerated return to prosperity and the realization of economic growth at a comparatively high level would reduce costs and alleviate the distress that a change in the system in the transition period would involve, helping to carry forward the reform smoothly. In other words, measures to be taken to improve the present situation of the 
Japanese economy do not differ significantly from what is required to build the future sustainable economy and society.

In order to emerge from the current stagnant state of the macro economy as soon as possible, it is necessary to reconstruct the financial system in such a way as would bring about efficiency of fund allocation and recover efficiency of the labor market. Some also pointed out that it will be difficult to achieve economic growth amid an increasingly ageing population unless a sound labor market and an efficient financial and capital market are established. Finding solutions for the bad loans and forming an efficient financial and capital market will not only make it possible to diversify portfolio selection and pension asset management of individuals but will allow enterprises to raise their funds efficiently. At the same time, there were many who expressed the opinion that the soundness of the Japanese economy would be recovered and a sustainable economy and society will be realized by defining public participation in the social security system (defining the roles which the public and the private sectors should play in social security) and building a safety net against various risks. As a timeworn story, it is pointed out that the formation of an efficient market through the improvement of various regulations and systems in the labor market will not only stimulate participation of the aged and women in the market and make up for the labor shortage but will also make a variety of employment forms feasible and contribute to the formation of a society in which people will feel that their life is worth living. There are also some who see the necessity of establishing the concept of equity in the social security system and employment of the aged, since these factors bear a significant relationship to the age at which payment of pensions is started, sustainability of the system and fair sharing of the pension cost between the young and the aged.

\section{RESOURCE AND ENVIRONMENTAL PROBLEMS}

Studies on resource/environmental problems reflect a closed-loop model of the economy and society. These studies are divided into four themes: (i) studies on waste management, which cover a wide variety of empirical studies; (ii) studies on sustainability and technological innovation related to resources/energy; (iii) studies on potential policies for addressing changes in climate; and (iv) studies on the relationship between environmental policies and economic policies, including employment policies.

From the standpoint of long-term sustainability of global resources, official involvement including policy measures and the development of new technology to remove environmental restrictions will be called for. There is a high possibility that new technology creates new products, stimulating 
demand, developing new industries with high productivity, and bringing about a renewed sustainable economic growth. New technology in the twenty-first century should contribute to the construction of the closedloop economy and society and enhance resources and energy efficiency, properly dispose of waste and increase efficiency of reusing resources. Furthermore, it must generate renewable energy efficiently and on a large scale. It may sound paradoxical, but past experience suggests that various restrictions imposed on economic activities, and the existence of regulation actually stimulates new technological development which helps to break through the restrictions.

Today, environmental issues encompass a very wide range of problems from territorial disposal of waste to the global environmental issues. It has been pointed out that a policy mix ingeniously combining such methods as regulatory and economic instruments, voluntary agreements and international emissions trading is essential for coping with these issues. What is important then is a policy which skillfully uses incentives, making use of market mechanisms. Japan is one of the most advanced countries in environment-related technology in the world. However, further technological breakthroughs will be called for in the future and it has been pointed out that use of market incentives and official support is essential in the fields where long-term risks are uncertain. It is suggested that concrete behavior by a community based on shared information (bottom-up approach) and a change in the behavior of individuals as consumers provide one of the keys in the closed-loop economy and society. Such a change in the behavior of individuals is caused by the diffusion and permeation of concepts such as the precautionary principle, one of the environmental principles in the European Union.

Addressing the construction of the closed-loop materials-cycle economy and society is important in the Japanese economy, which is faced with restrictions on resources and energy; it may be a way by which we can seek sustainable progress and growth of a Japanese type. Furthermore, some pointed out that, given its climatic and topographical conditions and its population density, the waste management system in larger Japanese cities could be a model for Asia and Japan will play an important role in the Asian area in coping with global environment issues.

\section{SYNTHETIC CONSIDERATION}

None of the various issues addressed in this project can be seen in isolation. They are closely related to one another and they will require simultaneous decision making by different parties when a desirable scenario is to be visu- 
alized. Ageing and the environment will both have a strong impact not only on the welfare of people today but also on that of future generations. An awareness of issues that are common to the ageing population and the environment is the context in which we should make use of market mechanisms.

There is a case for saying that we should make good use of market mechanisms by utilizing economic means in order to efficiently attain goals in health care and annuity, employment of the aged, women in the labor force, climatic change and waste disposal. However, many of these issues are examples of market mechanisms not functioning efficiently, or a 'failure' of the market. Utilizing market mechanisms in this domain involves various difficulties such as internalizing externalities and we cannot avoid classical problems such as efficiency and equity and what roles should be played by the public and private sectors.

Research into the ageing population and the environment has thrown into relief the importance of technological innovation. Looking back on human history, we find that restrictive conditions gave birth to technological innovation which presented a way out of the difficulties faced. Although the twenty-first century has severe restrictions imposed upon it such as resources, energy, labor force and population, we may also take a positive view and say that, conversely, the conditions are ripe for technological innovation. If we could achieve such innovation in this global situation, then a more enriched economy and society would develop.

In the short term, countries with ageing populations are likely to consume more energy - without any thought to the long-term impact of their consumption patterns and economic activity. This tendency must be offset by a new sense of sustainability, one that looks to the future, that thrives on improved resource/energy efficiencies, and that is based on ecofriendly waste disposal and new eco-friendly technologies. Without lowering living standards, we must solve global environmental problems, and overcome the constraints of limited energy resources. To do so will require the creation of a closed-looped economy/society. Failure to do so may spell the end to our way of life in the not-so-distant future.

In this project, we explore optimal solutions to social optimization problems. After taking into account the political and social constraints we face, and after alignment and coordination of the results of the studies, we will sketch out an ideal design and examine the possible direction of future research.

The project came to an end in March 2002. It solved many theoretical and empirical issues, but has created new areas for debate. Twice a year, all the members of the project, along with selected participants, met to discuss the results of the research. Unfortunately, it has not been possible to reproduce the fruitful discussion in this volume. 
Overall, the studies presented in the project were extremely challenging, and covered a wide range of topics. We hope that we shall soon have the opportunity to discuss the research once more from a common standpoint. The results are presented here as part of the ESRI studies series, available to policy makers, academics and businesspeople with a keen interest in these subjects. The series on ageing problems covers macroeconomics, social security and the labor market. Unfortunately, because of space limitations we are able to publish only some of the total output, selected by the members of the Editorial Board. We would like to acknowledge the ceaseless efforts of ESRI members throughout the project period, especially those from the Department of Administrative Affairs. Last but not least, we would like to thank Dymphna Evans, Matthew Pitman and Karen McCarthy from Edward Elgar Publishing.

Yutaka Kosai, President, ESRI 